\title{
Analysis of Risk Measures in Portfolio Optimization for the Uganda Securities Exchange
}

\author{
Criscent Birungi*, Lucy Muthoni \\ Strathmore University, Institute of Mathematical Sciences, Nairobi, Kenya \\ Email: *criscentbirungi@gmail.com
}

How to cite this paper: Birungi, C., \& Muthoni, L. (2021). Analysis of Risk Measures in Portfolio Optimization for the Uganda Securities Exchange. Journal of Financial Risk Management, 10, 135-152. https://doi.org/10.4236/jfrm.2021.102008

Received: April 22, 2021

Accepted: June 4, 2021

Published: June 7, 2021

Copyright $\odot 2021$ by author(s) and Scientific Research Publishing Inc. This work is licensed under the Creative Commons Attribution International License (CC BY 4.0).

http://creativecommons.org/licenses/by/4.0/

\section{(c) (i) Open Access}

\begin{abstract}
For the most recent years, risk has become one of the essential parameters in portfolio optimization problems. Today most practitioners and researchers in portfolio optimization have used variance as a standard risk measure. This approach has been found subjective. The Markowitz (1952) mean-variance model considered variance as an adequate portfolio risk measure, and asset returns are multivariate normally distributed and that investors have a quadratic utility function which is subjective too. Other risk measures have been suggested to overcome the limitations of the mean-variance model. This paper analyzes which portfolio optimization models can better explain the optimal portfolio performance (high return, low risk) for the Uganda Security Exchange (USE). We compare Mean-Variance (MV), Mean Absolute Deviation (MAD), Robust Portfolios and Covariance Estimation Models (The Shrinked Mean-Variance (SMV) Models \& Alternative Covariance Estimator (ACE) Models) and Mean-Conditional Value-at-Risk (Mean-CVaR) models in terms of the risk and performance. For the computed monthly returns and price data (February 2010 to January 2021) for USE selected stocks, we considered the results to show that Mean-CVaR and ACE portfolios have the highest performance ratio compared to other models. We find that VaR is the best risk measure for portfolio optimization for the USE since it has lower values across all models than other risk measures. It is vital to consider all the available risk measures for a regulator or practitioner to make a good decision since using one can be subjective; as seen in our results, different risk measures yield different results.
\end{abstract}

\section{Keywords}

Portfolio Optimization, Risk Measures, Conditional Value-at-Risk, Variance, Uganda Security Exchange 


\section{Introduction}

\subsection{Background of the Study}

A portfolio is a collection of financial instruments. Portfolio optimization is the process of selecting the best portfolio (asset distribution) by the investor from a list of portfolios that will give him or her the highest level of return given an investment objective. Risk measures are tools used to assess the performance of an investment basing on the exposure and degree at which the associated prices move (Volatility). The question is which risk measure to be selected for the appropriate portfolio investment management.

\subsubsection{Modern Portfolio Theory (MPT)}

Markowitz (1959) laid the groundwork for MPT defining an investor's portfolio selection problem regarding expected return and variance of return. He postulates that an investor should maximize expected portfolio return while minimizing portfolio variance of return. Since the introduction of Markowitz (1952) Mean-Variance (MV) model, variance has become the most common risk measure in portfolio optimization. However, this model relies strictly on the assumption that the returns of assets are multivariate normally distributed or the investor's utility function is quadratic (Hoe et al., 2010). The most recent literature has shown that the Markowitz framework and MV formulation based on these two assumptions seem not to hold in the real market. Markowitz argues that given estimates of the returns, volatilities, and correlations of a set of investments and constraints on investment choices (Nduku, n.d.). From this, it is possible to perform an optimization that results in the risk/return, or mean-variance efficient frontier, according to him, this frontier is efficient because every portfolio on this frontier is a portfolio that results in the greatest possible expected return for that level of risk. However, it is observed that in postwar US data, the slope of the mean-standard deviation frontier is much higher than reasonable risk aversion and consumption volatility estimates suggest. Brooks and Kat (2002) also show that hedge funds returns are not normally distributed.

Therefore due to issues raised and limitations of Markowitz's (1952) MeanVariance (MV) model, different measures of risk measures in portfolio optimization have been proposed, such as Mean Absolute Deviation (MAD) by Konno and Yamazaki (1991), Minimax (MM) attributed to Young (1998), Albuquerque (2009) Beta models and Silva et al. (2017) Beta-Conditional Value-at-Risk (CVaR) models. There have been several studies in Portfolio optimization using different risk measures by employing portfolio optimization models. Mayanja (2011) urges that to carry out portfolio optimization, one needs software, which must have inbuilt algorithms. This means that for one to think about portfolio optimization, one should first be assured of a portfolio that exists, then the next step would be which percentages in terms of allocation should be allocated to each portfolio. Such portfolios are available in Stock (Securities) Exchanges where they are traded; in these exchange markets, buyers and sellers hold securi- 
ties and make transactions decisions when maturity (can be short or long term) reaches to exchange these assets. Literature shows stock markets play a vital role in developing economies in generating capital, especially where they are organized and efficient. Besides, there are some of the new trends in portfolio optimization, such as diversification methods, risk-parity portfolios, the mixing of different sources of alpha, and practical multi-period portfolio optimization (Silva et al., 2017).

\subsubsection{The Uganda Securities Exchange (USE)}

The Uganda Securities Exchange is one such stock market where portfolios are traded. The formal operation started in 1997 after USE's license by the Capital Markets Authority of Uganda. The USE began formal trading operations in January 1998 following the listing of its first instrument, the 4-year East African Development Bank (EADB) Bond. In January 2000, USE listed its first equity, Uganda Clays Ltd. (Mayanja, 2011; Uganda Securities Exchange, n.d.). Since 2000 , USE has been growing with more individual investors, and financial institutions listed hold shares of these companies at USE. Among the Securities currently traded at the Exchange include Government Bonds, Corporate Bonds, Commodities, and Ordinary Shares. However, Literature shows that risk measurement in terms of market analysis at USE has become more complex as more companies are listed. Individual investors and financial institutions prefer investment portfolios that are stable and with less volatility. Several finance models exist which can be used to determine returns and return volatility (Okumu \& Onyuma, 2015).

There exist portfolio optimization studies in the Uganda Security Exchange. Most of the studies conducted on portfolio optimization in Uganda Securities Exchange have concentrated on the tests for the stock performance of the models, generating more risk measures like volatility, Sharpe Ratio (SR), Risk Parity (RP), Expected Shortfall (ES) or CVaR which they used to assess stock performance (Baganzi et al., 2017). These studies conducted were on how the portfolio performs, but not on the investigation of which portfolio optimization models can better explain the portfolio performance in terms of return and risk for the Uganda Security Exchange. Therefore this justifies the purpose of our study on analysis of which portfolio optimization models Mean-Variance (MV), Mean Absolute Deviation (MAD), Robust Portfolios and Covariance Estimation Models (The Shrinked Mean-Variance (SMV) Models and Alternative Covariance Estimator (ACE) Models and Mean-Conditional Value-at-Risk (CVaR) models, can better explain the optimal portfolio performance in terms of returns and risk for the Uganda Security Exchange (USE).

\subsection{The Problem Statement}

One way of selecting optimal portfolios at USE is through market surveillance and speculation. However, USE is not mature enough to facilitate investors' investment choices, leading to the low utility of the same to the investors. Litera- 
ture shows that the approach of market surveillance and speculation is insufficient and subjective. One way of facilitating optimal investment portfolios in the market is by ensuring that the models used in portfolio optimization are as close to the actual market scenario as possible. Therefore, we want to answer the central question: Can we get an alternative method of selecting optimal portfolios at USE? To answer this question, we compared traditional portfolio optimization models to select optimal portfolios with the proposed risk models. We used variance, Covariance, Value-at-Risk ( $\mathrm{VaR})$ and Conditional Value-at-Risk ( CVaR) as risk measures to find out which model is efficient (high return, low risk) for USE.

\subsection{Objectives of the Study}

\subsubsection{Main Objective}

This study's main objective is to establish the best risk measure for Portfolio Optimization for the USE.

\subsubsection{Specific Objectives}

The specific objectives of this research are:

1) To develop optimal portfolios using the traditional portfolio optimization models and the proposed risk models at USE.

2) To analyze the performance of the portfolios in terms of returns at USE.

3) To analyze the risk associated with each portfolio using different risk measures at USE.

\subsection{Significance of the Study}

The study will:

1) To provide an alternative method of selecting optimal portfolios at USE.

2) Establish the best risk measure for Portfolio Optimization for the USE.

3) Develop portfolio optimization models to select an optimal portfolio for investment at Uganda Securities Market and other Ugandan financial institutions with interest in portfolio investment.

4) Add on the foundation and further research portfolio optimization on Securities Exchanges especially developing markets like USE.

We structured the rest of this paper as follows. The next section 2, the mathematics discusses the mathematical models, mainly traditional portfolio optimization models and the proposed risk models. Section 3 methods discusses data used, parameter estimation, portfolio compositions. In the later section 4 , we discuss the formed portfolios' computational and performance results by employing the five optimization models mentioned using the proposed data on section 3 of the Uganda Securities Exchange.

\section{The Mathematical Formulation for Optimal Portfolio Formation}

The data collected was used in testing and analysis of different risk measures in 
portfolio optimization for the Uganda Securities Exchange. Portfolios were developed by employing the MV (1), MAD (2), SMV (2.4.1), ACE (2.4.2) and Mean-CVaR (7) models to compare the portfolio performance in terms of returns and risk associated with each optimal portfolio. The data include computed monthly returns and prices for the period from February 2010 to January 2021. We employed different portfolio optimization models to form these optimal portfolios.

\subsection{Mean-Variance (MV) model}

As proposed by Markowitz (1952), the MV model seeks to minimize Variance $V(R)$ at a given level of expected returns $E(R)$ shown in Equation (1). Equation (1), together with its constraints, is the famous Markowitz's Mean-Variance Model, also commonly known as the Modern Portfolio Theory (MPT) model (Markowitz, 1952). Markowitz laid the groundwork for the modern portfolio theory. The MV model's objective is to find the weight of assets that will minimize the portfolio variance at a level of the required rate of return. This model is a quadratic programming model (Hoe et al., 2010). We formulate the mathematical model as follows:

$$
\operatorname{Minimize}\left\{\operatorname{Var}(R)=\sum_{j=1}^{N} \sum_{k=1}^{N} w_{j} w_{k} \sigma_{j k}\right\} .
$$

Subject to:

1) $E(R)=\sum_{j=1}^{N} w_{j} y_{j} \geq \rho W, \rho$ is a parameter representing the minimal rate of return required by an investor. Mean return, $E(R)$ of a portfolio exceeds some minimum $(\rho W)$.

2) $\sum_{j=1}^{N} w_{j} \leq W$, the total allocations to the portfolio do not exceed the budget $(W)$.

3) $0 \leq w_{j} \leq u_{j}$, for $j=1, \cdots, n$ and $n=1, \cdots, N$, maximum budget share that can be invested in assets $j$ is $u_{j}$.

4) $\sum_{j=1}^{N} w_{j}=1$, total allocations or portions or fraction of capital allocated in selected assets equals 1 , meaning all the money must be invested.

5) $\sigma_{j k}=\frac{1}{T-N} \sum_{t=1}^{T}\left(y_{j t}-y_{j}\right)\left(y_{k t}-y_{k}\right)$, is the covariance between assets $j$ and $k$. Parameters,

$N$ is the number of assets, $T$ is time, $y_{j t}$ is return of asset $j$ at time $t, y_{j}$ is the mean return of asset $j, y_{k t}$ is the return of asset $k$ at time $t, y_{k}$ is the mean return of asset $k, w_{j}$ is the portfolio allocation for asset $j, u_{j}$ is the maximum budget share that can be invested in assets $j . w_{k}$ is the portfolio allocation for asset $k$.

The Markowitz model's simplicity has made it popular, with only two summary statistics, i.e. mean and variance, to compute. We will employ Markowitz 
view that given estimates of the returns, volatilities, and correlations of a set of investments and constraints on investment choices, to perform an optimization that results in the risk/return or mean-variance efficient frontier that is efficient, i.e. every portfolio on this frontier is a portfolio that results in the greatest possible expected return for that level of risk. From Model (1),

$$
\begin{gathered}
\mu_{p}=\sum_{j=1}^{N} w_{j} y_{j}, \text { to denote portfolio average return, } \\
\sigma_{p}^{2}=\sum_{j, k=1}^{N} w_{j} w_{k} \sigma_{j k} \text { to denote portfolio variance. }
\end{gathered}
$$

Then $\mu_{p}$ and $\sigma_{p}^{2}$ will be the desired level of the expected return on the portfolio and ts variance, respectively.

\subsection{Mean-Absolute Deviation (MAD) Model}

Konno and Yamazaki (1991) proposed the Mean Absolute Deviation (MAD) model as a risk measure to overcome the Mean-Variance (MV) model's weakness. The MAD model assumes that the standard deviation is a satisfactory portfolio risk measure. MAD employs a mean's absolute deviation for measuring risk instead of the variance. Literature shows that if returns are normally distributed, both MAD, MV and MM yield the same results. Basing on (Konno \& Yamazaki, 1991), MAD is mathematically formulated as follows:

$$
\operatorname{Minimize} w(y)=E\left[\left(\mid \sum_{j=1}^{N} Y_{j} w_{j}-E\left[\sum_{j=1}^{N} Y_{j} w_{j}\right]\right) \mid\right],
$$

Subject to

1) $\sum_{j=1}^{N} w_{j} Y_{j} \geq \rho W, \rho$ is a parameter representing the minimal rate of return required by an investor. This constraint means portfolio expected return exceeds some minimum $(\rho W)$.

2) $\sum_{j=1}^{N} w_{j} \leq W$ the total allocations to the portfolio do not exceed the budget (W).

3) $0 \leq w_{j} \leq u_{j}$, for $j=1, \cdots, n$ and $n=1, \cdots, N$, maximum budget share that can be invested in assets $j$ is $u_{j}$.

4) $\sum_{j=1}^{N} w_{j}=1$, total allocations or portions or fraction of capital allocated in selected assets equals 1, meaning all the money must be invested.

Parameters,

$N$ is the number of assets, $T$ to be used later is the time, $Y_{j}$, is a random variable representing return per period for asset $j, w_{j}$, is portfolio allocation to asset $j, u_{j}$, is the maximum budget share that can be invested in asset $j, \rho W$ is the minimum level of return, $W$ is the total allocation. Konno and Yamazaki (1991) assume that the expected value can be approximated by the average over 
time so that,

$$
r_{t}=E\left[Y_{j}\right]=\frac{1}{T} \sum_{j=1}^{N} y_{j t}
$$

Here, $y_{j t}$ is the realization of random variable $Y_{j}$ during period $j$. Substituting Equation (3) into Equation (2) we have Equation (4)

$$
w(y)=E\left[\left|\left(\sum_{j=1}^{N} Y_{j} w_{j}-E\left[\sum_{j=1}^{N} Y_{j} w_{j}\right]\right)\right|\right]=\frac{1}{T} \sum_{j=1}^{N}\left[\left|\left(\sum_{j=1}^{N}\left(y_{j t}-y_{j}\right) w_{j}\right)\right|\right]
$$

From Equation (4) by letting $z_{j t}=y_{j t}-y_{j}$ and simplifying (4) we have Equation (5) and now the optimization problem in (2) can be written as,

$$
\text { Minimize } w(y)=\frac{1}{T} \sum_{j=1}^{N} z_{j t} w_{j}
$$

Subject to the same constraints in Equation (2). By simplifying Equation (5) further that is $z_{j t} w_{j}=b_{t}$ for $t=1, \cdots, T$ we have,

$$
\text { Minimize } w(y)=\frac{1}{T} \sum_{j=1}^{N} b_{t}
$$

Subject to

1) $b_{t} \pm \sum_{j=1}^{N} z_{j t} w_{j} \geq 0, t=1, \cdots, T, b_{t}$ is a linear form to represent returns on asset $j$ at time $t$ with respective portfolio allocation $w_{j}$. This constrain accounts for the deviation of the values below and above the expected value of the portfolio.

2) $\sum_{j=1}^{N} w_{j} Y_{j} \geq \rho W, \rho$ is a parameter representing the minimal rate of return required by an investor. This constraint means portfolio expected return exceeds some minimum $(\rho W)$.

3) $\sum_{j=1}^{N} w_{j} \leq W$, the total allocations to the portfolio do not exceed the budget $(W)$.

4) $0 \leq w_{j} \leq u_{j}, j=1, \cdots, N$, maximum budget share that can be invested in assets $j$ is $u_{j}$.

5) $\sum_{j=1}^{N} w_{j}=1$, total allocations, portions of capital allocated in selected assets should be 1 , meaning all the money must be invested.

Equation (6), together with its constraints, becomes our linear optimization problem. Hoe et al. (2010) show that there is no need to calculate the covariance matrix for this linear problem. Furthermore, it is a linear program and Equation (6) penalizes both negative and positive deviations. Literature shows that investors prefer higher positive deviations and avoid lower negative deviations in portfolio return (Hoe et al., 2010).

\subsection{Mean-CVaR Models}

Most literature shows that traditional optimization models fail to provide efficient portfolios, especially when financial assets' returns are highly volatile, Silva 
et al. (2017). Various risk measures have been proposed as an alternative to variance. $\mathrm{VaR}$ is one of such proposed risk measures. $\mathrm{VaR}$ is the maximum value one stands to lose for a given period at a given confidence level. VaR's weakness is that it does not tell the amount or magnitude of the actual loss after VaR estimate, which occurs with probability $(1-\alpha)$. For example, if the $99 \% \mathrm{VaR}$ is, say, 2 million Kshs, we would expect to lose not more than 2 million Kshs with $99 \%$ confidence, but we do not know what amount the actual loss would be after (1 a). CVaR, also referred to as Expected shortfall (ES), was proposed to overcome such a challenge. The Expected shortfall (ES) estimate is the expected loss given that the portfolio return already lies below the pre-specified worst-case quantile return. This approach is fundamental, especially if we experience a catastrophic event; this can tell us the expected loss in our financial position. Würtz et al. (2015) propose the Mean-CVaR Model where covariance risk now replaced by the CVaR as the risk measure. MV model (1) considered variance as a satisfactory portfolio risk measure; asset returns are multivariate normally distributed, investors have a quadratic utility function which is subjective. This model no longer restricts the set of assets to have a multivariate elliptically contoured distribution, reducing distribution bias and improving computational efficiency. Basing on Würtz et al. (2015) Mean-CVaR model is mathematically formulated as follows,

$$
\begin{gathered}
\operatorname{Min}_{w} \operatorname{CVaR}_{\alpha}(w), \\
\text { s.t } \quad w^{\mathrm{T}} \hat{\mu}=\bar{r}, \\
w^{\mathrm{T}} \hat{1}=1 .
\end{gathered}
$$

where,

1)

$$
\operatorname{CVaR}_{\alpha}(w)=\frac{1}{1-\alpha} \int_{f(w, r) \leq \operatorname{VaR}_{\alpha}(w)} f(w, r) p(r) \mathrm{d} r,
$$

$\mathrm{CVaR}_{\alpha}$ is the Conditional Value at Risk associated with portfolio $W, f(w, r)$ denote the loss function when we choose the portfolio $W$ from a set $X$ of feasible portfolios, $r$ is the realization of the random events with a probability density function denoted by $p(r)$.

2)

$$
\operatorname{VaR}_{\alpha}(w)=\min \{\gamma \in \mathcal{R}: \Psi(w, \gamma) \geq \alpha\}
$$

$V a R_{\alpha}$ is the Value at Risk associated with portfolio $W$, with a given confidence level $\alpha$,

3)

$$
\Psi(w, \gamma)=\int_{f(w, r) \leq \gamma} p(r) \mathrm{d} r
$$

$\Psi(w, \gamma)$ is the cumulative distribution function of the loss associated with a fixed decision vector $w$.

Since Equation (7) is an optimization problem, the author proposes minimizing $\mathrm{CVaR}_{\alpha}$ and $\operatorname{VaR}_{\alpha}$ are not equivalent. They, therefore, consider the fol- 
lowing more straightforward auxiliary function,

$$
F_{\alpha}(w, \gamma)=\gamma+\frac{1}{1-\alpha} \int_{f(w, r) \leq \gamma}(f(w, r)-\gamma) p(r) \mathrm{d} r .
$$

The $F_{\alpha}(w, \gamma)$ function in (8) has the important properties that make it useful for the computation of $C_{V a R_{\alpha}}$ and $\operatorname{VaR}_{\alpha}(w)$, for example $F_{\alpha}(w, \gamma)$ is a convex function of $\gamma, \operatorname{VaR}_{\alpha}(w)$ is a minimizer of $F(w, \gamma)$ and the minimum value of the function $F_{\alpha}(w, \gamma)$ is $C V a R_{\alpha}$. The latter follows performing an optimization following (7).

\subsection{Robust Portfolios and Covariance Estimation Models}

Würtz et al. (2015) proposed Robust Portfolios and Covariance Estimation Models to compute the mean and covariance matrix of the set of financial assets to achieve better stability properties compared to traditional minimum variance portfolios. We use two different approaches implemented by Würtz et al. (2015) that is robust mean and covariance estimators, and the shrinkage estimator.

\subsubsection{The Shrinked Mean Variance (SMV) Models}

Würtz et al. (2015) considered a convex combination of the empirical estimator with some suitable chosen target. According to the Authors, a mixing parameter was selected to maximize the expected accuracy of the shrinked estimator; this was done by using an analytic estimate of the shrinkage intensity. Unlike the computational cost required in the MV model (1), Shrinked Mean-Variance Models increases and in terms of boundness, shrinkage estimate is always positive definite and well-conditioned, which is advantageous in terms of convergence.

\subsubsection{Alternative Covariance Estimator (ACE) Models}

Würtz et al. (2015) provide an alternative to estimate covariance from an R's recommended packages, such as MASS, which has inbuilt functions to generate optimal portfolios. We apply this method on the 11 years' historical price data (132 months from 2010-02-26 to 2021-01-26) for nine stocks listed on the LSI USE indexes to compare the performance of this model with other models.

\section{Methods}

\subsection{Data Collection}

This study uses secondary data (computed monthly returns and prices for the selected stocks from February 2010 to January 2021) from USE Local Share Index (LSI), which tracks only the USE's local companies. This period was not randomly selected; we chose this period because the Ugandan economy reported solid economic growth, especially from 2016 to 2019, estimated at 6.3\%, the expansion of services drove this. We considered nine stocks, Uganda Clays Ltd (UCL), British American Tobacco Uganda Ltd. (BATU), Bank of Baroda Ltd. (BOBU), Development Finance Company of Uganda Ltd. (DFCU), New Vision Printing and Publishing Company Ltd. (NVL), Stanbic Bank Uganda (SBU), National Insurance Corporation (NIC), UMEME Ltd. (UMEM) and Stanbic Bank 
Uganda (UGA) DEAD stock listed at USE. The nine stocks we considered were randomly selected for the analysis. There are also cross border companies listed on the Uganda Securities Exchange, which are East African Breweries Ltd., Kenya Airways, Jubilee Holdings Ltd., Equity Bank Ltd., Kenya Commercial Bank Ltd., Nation Media Group, Centum, UCHUMI) among others. Mathematically the nine stocks out of seventeen stocks by then we consider will be an excellent sample to represent the whole stocks listed at USE for this analysis to study the portfolio composition and risk measures. Information on the trading dates, opening price, closing price, Stock names, low/high prices, the volume traded was collected from the USE website. Using a data collection sheet, we only considered stock names, trading dates, and closing prices since we are interested in calculating expected values, standard deviation, and correlations of stock returns to calculate expected returns and volatilities of these stocks. The monthly returns were computed using Equation (9) from February 2010 to January 2021.

\subsection{Parameter Estimation}

Parameters in the Mean-CVaR and Robust Portfolios and Covariance Estimation Models

Different R packages under library (fPortfolio) were used to estimate most parameters for the computed monthly returns data for each of the selected stocks using Equation (9) while performing the optimization of portfolios. The $(1-\alpha)$ is the confidence level.

\subsection{Data Analysis}

We used the 11 years' historical price data (132 months from 2010-02-26 to 2021-01-26) for nine stocks listed on the LSI USE indexes from the USE website (https://www.use.or.ug/). We computed the returns for each stock at the monthly price for the monthly prices of the selected stocks at the monthly price, which we used for analysis. For analysis purposes, we assigned zeros( 0 prices $)$ where the stock was not traded, for example, the first two months of NIC stock and the first 35 months of UMEM stock. The sample of the first 12 months of 132 months for the selected stock prices are as shown on Figure 1.

Figure 1 only exemplifies the sample of the first 12 months of 132 months for stock prices we considered for this study.

We then computed the monthly returns for each of the selected stocks using Equation (9) below,

$$
r_{i, t+1}=\ln \left(\frac{P_{i, t+1}}{P_{i, t}}\right) \text { for } i=1, \cdots, 9 \text { and } t=0, \cdots, 131 .
$$

where, $i$ denote the stock number, $t$ denotes the period in months, $P_{i, t+1}$ denote the stock $i$ price at month $t+1, P_{i, t}$ denotes the stock $i$ price at month $t$ and $r_{i, t+1}$ denote the stock $i$ return at month $t+1$. We used Equation (9) to compute the stock returns from 2010-02-26 to 2021-01-26. The logs of non-numerical numbers were assigned zeros for easy analysis. Again, the sample of the first 12 
months of 132 months for the selected stock returns are as shown on 2 below, Figure 2 only exemplifies the sample of the first 12 months of 132 months for stock returns we considered for this study. Figure 3 shows the USE LSI selected stock returns movements over 2010-02-26 to 2021-01-26 in terms of performance and volatility.

\subsection{Portfolio Compositions}

Basing on the mathematical framework of MV (1), MAD (2), Mean-CVaR (7) models and Robust Portfolios and Covariance Estimation Models in subsection, (2.4), Portfolios were developed. Weights were assigned on the selected stocks using different techniques, for example, equal weights feasible portfolio with "LongOnly" constraints and others we consider optimal portfolio allocation using

\begin{tabular}{|c|c|c|c|c|c|c|c|c|c|}
\hline$\wedge$ & BOBU & BATU & DFCU & NIC & NVL & SBU & UCL & UMEM & UGA \\
\hline $2010-02-26$ & 67.68 & 250 & 310.00 & NA & 464.00 & 16.50 & 50.00 & NA & 82.5 \\
\hline $2010-03-26$ & 66.24 & 295 & 340.00 & NA & 480.00 & 18.60 & 65.00 & NA & 93.0 \\
\hline $2010-04-26$ & 74.40 & 320 & 353.00 & 22.38 & 540.00 & 21.00 & 76.00 & NA & 105.0 \\
\hline $2010-05-26$ & 105.60 & 320 & 400.00 & 22.38 & 720.00 & 20.00 & 51.00 & NA & 100.0 \\
\hline $2010-06-26$ & 102.00 & 320 & 400.00 & 24.24 & 730.00 & 20.50 & 55.00 & NA & 102.5 \\
\hline $2010-07-26$ & 102.00 & 330 & 400.00 & 26.11 & 765.00 & 22.50 & 60.00 & NA & 112.5 \\
\hline $2010-08-26$ & 103.20 & 330 & 402.50 & 26.11 & 791.00 & 23.50 & 60.00 & NA & 117.5 \\
\hline $2010-09-26$ & 106.80 & 330 & 405.00 & 26.11 & 817.00 & 24.50 & 55.00 & NA & 122.5 \\
\hline $2010-10-26$ & 111.60 & 1010 & 407.50 & 26.11 & 765.00 & 26.20 & 53.00 & NA & 131.0 \\
\hline $2010-11-26$ & 115.20 & 1250 & 407.50 & 26.11 & 645.00 & 26.50 & 52.00 & NA & 132.5 \\
\hline $2010-12-26$ & 120.00 & 1740 & 410.00 & 26.11 & 610.00 & 26.50 & 45.00 & NA & 132.5 \\
\hline $2011-01-26$ & 130.80 & 1740 & 425.00 & 26.11 & 525.00 & 27.50 & 50.00 & NA & 137.5 \\
\hline
\end{tabular}

Figure 1. Sample of the first 12 months of 132 months of the stock prices.

\begin{tabular}{|c|c|c|c|c|c|c|c|c|c|}
\hline$\Delta$ & вовU & BATU & DFCU & NIC & NVL & SBU & UCL & UMEM & UGA \\
\hline 2013-01-26 & 0.113328685 & -0.0105356550 & 0.0000000000 & 0.000000000 & 0.000000000 & 0.2231435513 & 0.154150680 & 0.0357180826 & 0 \\
\hline 2013-02-26 & 0.292136423 & -0.0004414037 & 0.0295588022 & 0.000000000 & 0.000000000 & 0.0000000000 & 0.000000000 & 0.0512932944 & 0 \\
\hline 2013-03-26 & 0.000000000 & 0.0004414037 & 0.0000000000 & 0.000000000 & 0.000000000 & 0.0000000000 & 0.000000000 & 0.0000000000 & 0 \\
\hline 2013-04-26 & -0.223143551 & 0.0000000000 & 0.0000000000 & 0.000000000 & 0.000000000 & 0.1823215568 & 0.000000000 & 0.0487901642 & 0 \\
\hline 2013-05-26 & 0.080042708 & -0.0004414037 & 0.0000000000 & 0.000000000 & 0.000000000 & -0.0689928715 & 0.000000000 & 0.1609303668 & 0 \\
\hline 2013-06-26 & -0.080042708 & 0.0022050726 & 0.0000000000 & 0.000000000 & 0.000000000 & 0.0689928715 & -0.154150680 & -0.0699585886 & 0 \\
\hline 2013-07-26 & 0.000000000 & 0.1123842495 & 0.0058083416 & 0.000000000 & 0.000000000 & -0.1823215568 & 0.000000000 & 0.0425596144 & 0 \\
\hline 2013-08-26 & -0.042559614 & 0.0000000000 & -0.0009657171 & 0.000000000 & 0.008298803 & 0.0000000000 & 0.000000000 & 0.0000000000 & 0 \\
\hline 2013-09-26 & 0.122602322 & 0.4541302801 & -0.0048426245 & 0.000000000 & 0.000000000 & 0.0000000000 & 0.000000000 & 0.0137933221 & 0 \\
\hline 2013-10-26 & 0.000000000 & 0.0124225200 & 0.0048426245 & 0.000000000 & 0.040491361 & 0.1823215568 & 0.000000000 & 0.0000000000 & 0 \\
\hline $2013-11-26$ & -0.080042708 & 0.0000000000 & 0.1395518804 & -1.822100186 & 0.000000000 & 0.0000000000 & 0.000000000 & 0.0270286724 & 0 \\
\hline $2013-12-26$ & -0.042559614 & 0.0000000000 & 0.0000000000 & 1.789386989 & 0.000000000 & -0.1823215568 & 0.000000000 & -0.0270286724 & 0 \\
\hline
\end{tabular}

Figure 2. Sample of the some of 12 months of 132 months of the stock returns. We show from 2013-01-26 since the values before this trading date has infinite numbers. 


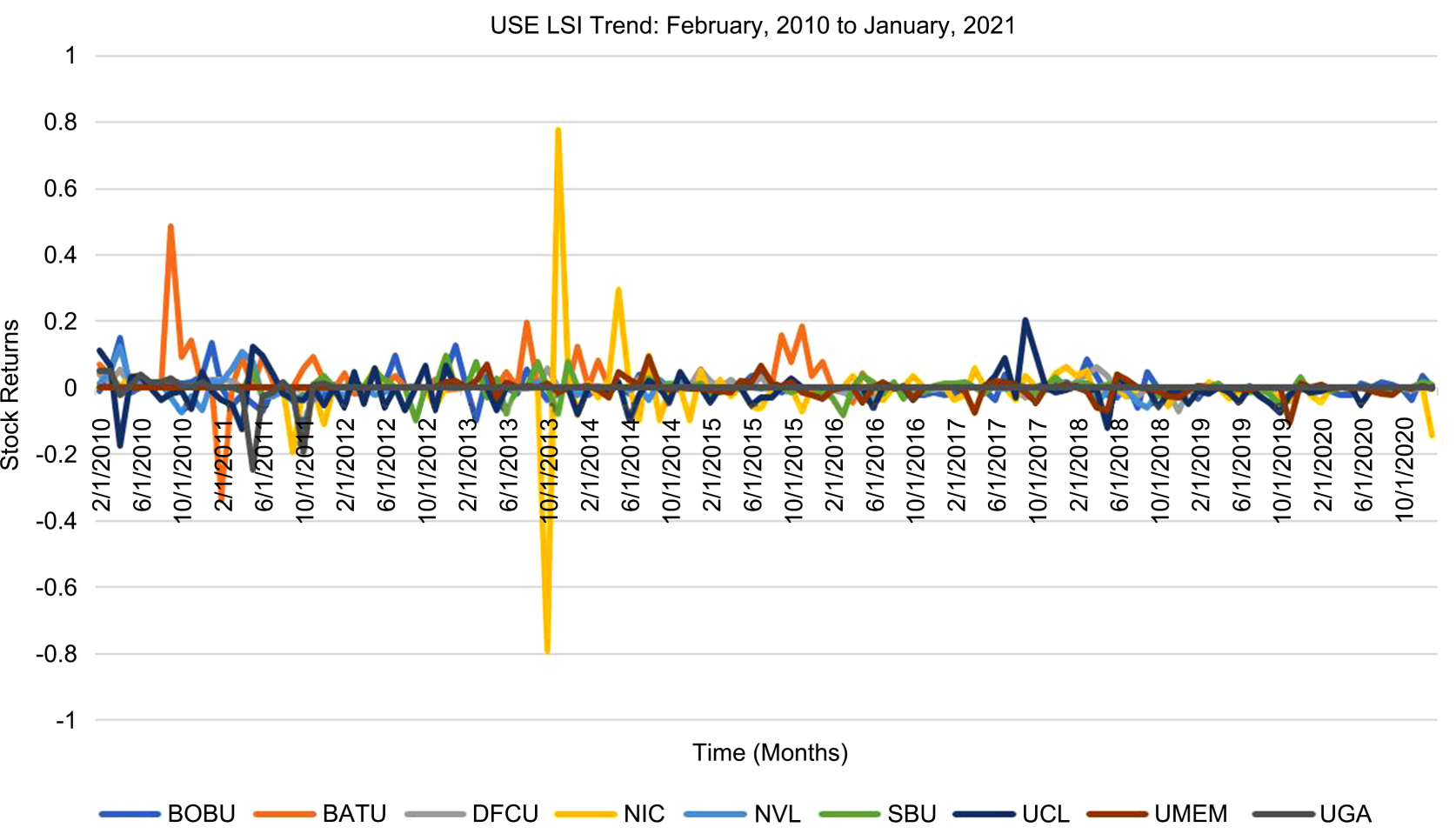

Figure 3. USE LSI selected stock Returns movements over the period of 2010-02-26 to 2021-01-26. Source: (https://www.use.or.ug/). This time-series graph shows the logarithmic returns of nine assets (stocks) included in the USE Local Share index. Figure 3 illustrates the stock returns movements throughout 2010-02-26 to 2021-01-26 (132 months) for stock returns we considered for this study. NIC stock being a highly volatile stock compared to others. BATU was also highly volatile between 2010-08-01 to 2011-11-01 and 2013-01-01 to 2016-02-01 and lowered later. UCL's returns were highly volatile between 2017-01-01 to 2018-08-01. Other stocks' volatility are skewed around zero $(0)$.

setWeights() function, which is the default case. With the collected data that is, Computed monthly returns and prices for the period February 2010 to January 2021 for nine stocks; Uganda Clays Ltd. (UCL), British American Tobacco Uganda Ltd. (BATU), Bank of Baroda Ltd. (BOBU), Development Finance Company of Uganda Ltd. (DFCU), New Vision Printing and Publishing Company Ltd. (NVL), Stanbic Bank Uganda (SBU), National Insurance Corporation (NIC), UMEME Ltd. (UMEM), and Stanbic Bank Uganda(UGA) DEAD stock. We then allocated these weights in percentages of each stock based on the five optimization models to develop five optimal portfolios. The portfolio compositions are shown on Table 1.

The results in Table 1 show portfolios generated by the five portfolio optimization models and their compositions. Due to differences on the weight of stocks, results from portfolio compositions normally differ. Difference in weight may be probably due to the non-normality displayed by data (Byrne \& Lee, 2004). For example, different stocks have different performance over time. We used different optimal asset allocations techniques to attach weights on all assets. In section 4, we use Variance (Sigma), Covariance, Value at Risk (VaR) and Conditional Value at Risk $(\mathrm{CVaR})$ as risk measures for all the five optimal portfolios to compare which model is efficient (high return, low risk) for USE. 
Table 1. Optimal portfolio compositions of five different models.

\begin{tabular}{cccccc}
\hline \multicolumn{5}{c}{ Portfolio Weights } \\
\hline Stocks & $\begin{array}{c}\text { Mean-CVaR } \\
(7)(\%)\end{array}$ & $\begin{array}{c}\text { MAD } \\
(6)(\%)\end{array}$ & $\begin{array}{c}\text { MV } \\
(1)(\%)\end{array}$ & $\begin{array}{c}\text { SMV } \\
(2.4 .1)(\%)\end{array}$ & $\begin{array}{c}\text { ACE } \\
(2.4 .2)(\%)\end{array}$ \\
\hline UCL & 0.00 & 2.03 & 5.07 & 15.48 & 0.48 \\
BATU & 24.27 & 9.69 & 1.53 & 00.00 & 2.47 \\
BOBU & 0.39 & 3.39 & 3.00 & 4.11 & 0.49 \\
UGA & 74.83 & - & - & 21.63 & 81.32 \\
NVL & 0.00 & 42.58 & 55.82 & 28.83 & 7.93 \\
UMEM & 0.15 & 6.19 & 5.71 & - & - \\
NIC & 0.02 & 1.67 & 1.39 & 1.80 & 00.52 \\
SBU & 0.34 & 9.65 & 6.45 & 8.07 & 00.17 \\
DFCU & 0.00 & 24.80 & 21.03 & 20.09 & 6.62 \\
\hline
\end{tabular}

\section{Results and Discussion}

\subsection{Measuring Portfolio Performance, Expected Return and Risk}

\subsubsection{Risk Measure Performances}

In terms of risk measure for each portfolio discussed in subsection (1.2), we illustrated the portfolio compositions and how risk measure would be the best based on the lowest values. Therefore, we use this reference (taking the smallest value for each risk measure of each portfolio as the risk measure value), as summarized in Table 2.

Table 2 presents the results of the investment portfolios and the risk measures. We analyzed only the Variance, Covariance, $V a R$ and the $C V a R$. The reason for this is that both risk measures or measures of dispersion have the same unit of measurement. The portfolios generated using traditional portfolio optimization models i.e. Markowitz's based models (MAD (6), MV (1) and SMV (2.4.1)) except ACE (2.4.2) with covariance 4.0759 (higher covariance than the Mean-CVaR model) showed lower values in terms of risks. This result is consistent with Silva et al. (2017). The values of the Covariance, Variance, VaR were lower for MAD (6), MV (1) and SMV (2.4.1) models while $C V a R$ has higher values across all portfolios or models except in Mean-CVaR (7) model, this is because the primary objective of Mean-CVaR model is to minimize the $C V a R$ as a risk measure. When we considered all the assets (9) for the Mean-CVaR portfolio to make sure all assets are represented, there was a reduction in the risk (lower values of the risk measures), that is when we reduced assets from 9 to 7 assets on the Mean-CVaR portfolio the values for risk measures Covariance, $\operatorname{VaR}$ and the $C V a R$ increased. This result shows that a portfolio with more assets performs better in terms of risk. From Table 2, in terms of which risk measure would be the best (lower values), we observe that regardless of the primary objective of some models, for example, minimizing variance for the Markowitz's 
Table 2. Different risk measures in portfolios.

\begin{tabular}{cccccc}
\hline \multicolumn{5}{c}{ Risk measure estimates in optimal portfolios } \\
\hline Model & No. of assets & $\begin{array}{c}\text { Variance } \\
\text { (Sigma) }\end{array}$ & Covariance & $\begin{array}{c}\text { VaR } \\
\text { (C.I of 95\%) }\end{array}$ & CVaR \\
\hline Mean-CVaR & 9 & - & 3.5993 & 3.8959 & 0.5816 \\
MAD & 8 & - & 1.8806 & 2.5374 & 4.5954 \\
MV & 8 & - & 1.8332 & 0.0441 & 2.4103 \\
SMV & 8 & 2.7981 & 2.5374 & 0.1997 & 6.6736 \\
ACE & 8 & 0.4938 & 4.0759 & 0.1997 & 6.6138 \\
\hline
\end{tabular}

based models and minimizing CVaR for the Mean-CVaR models, the results we get some violet the models' primary objectives. For example, the results in Table 2 show that for MV (1) model whose primary objective is to minimize variance or covariance, $\operatorname{VaR}$ has the lowest value of 0.0441 compared with the Cov value of 18332. Therefore, taking variance or covariance from the MV (1), which takes variance or covariance as a risk measure, would not be optimal since $V a R$ has better values than other risk measures. This result is the same for both SMV (2.4.1)) Moreover, ACE (2.4.2) models have a lower $V a R$ of 0.1997 compared to Cov and Sigma's higher values. Only Mean-CVaR and MAD models results are consistent with these models' primary objective, which is minimizing portfolio $C V a R$ and $M A D$ or $\mathrm{Cov}$ receptively for the two models. For the Mean-CVaR portfolio, $C V a R$ has the lowest value of 0.5816 compared to higher values of $\mathrm{CoV}$ and $V a R$ hence $C V a R$ would the best risk measure for the Mean-CVaR portfolio. For the MAD portfolio, Cov has the lowest value of 1.8806 compared to higher values of $\operatorname{VaR}$ and $C V a R$; hence $C o v$ would the best risk measure on the MAD portfolio.

\subsubsection{Portfolio Performances}

In this subsection, we analyze the five models' portfolio performances discussed in (3.3) for the five models. We compare the performance of the traditional portfolio optimization models and the proposed risk models at USE. For the portfolios generated using Markowitz's based models, we considered variance or covariance as risk measures that is, by taking the smallest value of variance or covariance of each portfolio as the risk measure value) while for the mean-CVaR portfolio model, we considered the lowest value of conditional Value at Risk as the risk measure in this portfolio. For the portfolio expected return, we considered the highest fraction value of mean in each portfolio as the Expected Return of that particular portfolio, as shown in Table 3. Using this criterion, we considered the lowest value of mean absolute deviation or covariance as a risk measure in the MAD portfolio for the MAD portfolio. For MV, SMV and ACE, we used the lowest values of variance or covariance as a risk measure; for this case, for the MV, we took the smallest covariance of 1.8332 as the risk measure, 
Table 3. Summary statistics of optimal portfolios.

\begin{tabular}{cccccc}
\hline & Mean-CVaR & MAD & MV & SMV & ACE \\
\hline Expected Return & 0.6382 & 0.0002 & 0.6382 & 0.8805 & 0.8805 \\
Risk & 0.5816 & 1.8806 & 1.8332 & 2.5374 & 0.4938 \\
Performance & 1.097318 & 0.000106349 & 0.3481344 & 0.3470087 & 1.783111 \\
\hline
\end{tabular}

for SMV, we took the lowest covariance value of 2.5374 since it is the smallest among the covariance and sigma values available and the 0.4938 for ACE portfolio. For the Mean-CVaR portfolio, we considered the smallest value of $C V a R$ as the risk measure.

The results from Table 3 show the performance of different portfolios. Both SMV (2.4.1) and ACE (2.4.2) portfolios have the highest mean return of 0.8805 compared to other models. SMV (2.4.1) is the riskiest portfolio with 2.5374, while Mean-CVaR (7) and ACE (2.4.2) have the lowest risks of 0.5816 and 0.4938 , respectively. This result is because the primary objective of Mean-CVaR (7) and ACE (2.4.2) is to minimize CVaR and Covariance, respectively. With the lowest risk of Mean-CVaR (7) and ACE (2.4.2) portfolios, they have the highest performance ratio of 1.097318 and 1.783111 , respectively. The portfolio performance was calculated using the reward per risk equation as shown in (10). MAD (6) model has the lowest performance among other models.

$$
\text { Portfolio Performance }=\frac{\text { Portfolio Mean Return }}{\text { Portfolio risk }} .
$$

\section{Conclusion and Recommendations}

\subsection{Conclusion}

This study's main intention was to establish the best risk measure for portfolio optimization for the Uganda Securities Exchange (USE) and an alternative method of selecting optimal portfolios adopted in the USE. This involved:

1) Developing optimal portfolios;

2) Analyzing the performance of the portfolios in terms of returns; and

3) Analyzing the risk associated with each portfolio using different risk measures.

We used the USE secondary data (computed monthly returns and prices for the selected stocks from February 2010 to January 2021) from USE Local Share Index (LSI). We considered a sample of nine stocks from the USE Local Share Index. We chose nine stocks out of seventeen. Mathematically the nine stocks out of seventeen stocks listed at USE by then will be an excellent sample to represent the whole stocks listed at USE for this analysis to study the portfolio composition and risk measures.

There are concerns about model appropriateness for portfolio optimization. Hoe et al. (2010) find that some traditional portfolio optimization models are appropriate for investors who have a substantial downside risk aversion but not 
all of them. There was a general weakness of market surveillance and speculation method of selecting optimal portfolios in the literature, especially in developing markets. This study compared traditional portfolio optimization models to determine optimal portfolios with the proposed risk models. We used variance, Covariance, Value-at-Risk (VaR) and Conditional Value-at-Risk (CVaR) as risk measures to find out which model is efficient (high return, low risk) for USE.

We analyzed different portfolio optimization models by comparing the risk measures (comparing risk measure estimates) in all portfolios. We developed portfolios, measured their performances in terms of the return and the risk associated with each portfolio. We used five portfolio optimization models, MV (1), MAD (2), SMV (2.4.1), ACE (2.4.2) and Mean-CVaR (7), to come up with five optimal portfolios. We compared the portfolios' performance and risk measure estimates in all the portfolios. SMV (2.4.1) and ACE (2.4.2) portfolios produced the highest mean return of 0.8805 compared to other models. SMV (2.4.1) was the riskiest portfolio with 2.5374, while Mean-CVaR (7) and ACE (2.4.2) had the lowest risks of 0.5816 and 0.8805, respectively. Mean-CVaR (7) and ACE (2.4.2) portfolios had the highest performance ratio of 1.097318 and 1.783111, respectively, among other models.

We then compared the expected return and risk of the best performing models. In this case, we concluded that the Mean-CVaR (7) and ACE (2.4.2) in terms of both the expected return and risk. We find that ACE (2.4.2) performs better than the Mean-CVaR (7), with a performance ratio of 1.097318 and 1.783111, respectively. In terms of risk, ACE (2.4.2) was less risky than Mean-CVaR (7) though the difference was not too big. After considering all the factors, we conclude that the traditional portfolio optimization models generated an optimal portfolio with a higher return. The proposed risk models develop portfolios with less risk.

We also find that it is not about a specific risk measure; what matters is allocating weights to assets in a portfolio and the optimization method. Portfolios with more assets are less risky, i.e. lower risk measures' estimates were observed in portfolios with more stocks than those with fewer assets. However, we would like to quote the "decision on which risk measure to use should depend on the regulator or practitioner's intended use”. Regulators or Practitioners should focus on the strengths and weaknesses of each if they are to adopt it. It is crucial to consider all the available risk measures for a regulator or practitioner to make a good decision since using one can be subjective; as seen in our results, "different risk measures yield different results".

\subsection{Recommendations}

1) This study analyzed several risk measures for the Uganda Securities Exchange (USE) that researchers have proposed. Based on our findings, some yields good results; we, therefore, recommend regulators at Uganda Securities Exchange (USE) and other financial institutions in Uganda and globally adopt 
these risk measures as some favour regulators. For example, these risk measures allow banks, practitioners to safeguard against bank insolvency, bank failure and bankruptcy and other related challenges. They should focus on the strengths and weaknesses of each if they are to adopt it. It is crucial to consider all the available risk measures for a regulator or practitioner to make a good decision since using one can be subjective. As seen in our results, different risk measures yield different results. Further, we would like to recommend regulators at the Uganda Securities Exchange (USE) and other financial institutions in Uganda and globally adopt traditional portfolio optimization models and the proposed risk models as an alternative method of selecting optimal portfolios.

2) We lacked enough tools to run different optimizations, especially on the models. The different types of portfolio optimization models and different $\mathrm{R}$ packages under the library (fPortf olio) we used in optimal portfolio formation, were not efficient computationally. To overcome the computational inefficiency, further research on portfolio optimization at USE and other financial markets while comparing different portfolio optimization models for many assets should consider using other softwares that can perform the optimization. Other methods like Eigen decomposition-based methods can be used. The Eigen decomposition-based methods are recommended to obtain high-quality bounds on the optimal portfolios' solutions of traditional portfolio optimization problems and the proposed risk models with and without cardinality constraints.

\section{Acknowledgements}

I want to thank the DAAD for financial support towards this study. Furthermore, to my supervisor, Dr. Lucy Muthoni, we have made this study successful for the fantastic guidance and discussions we have made. I would also like to thank Dr. Fred Mayambala for his insights on the models' optimization.

\section{Conflicts of Interest}

The authors declare no conflicts of interest regarding the publication of this paper.

\section{References}

Albuquerque, G. U. V. D. (2009). Um estudo do problema de escolha de portfólio ótimo. Doctoral Dissertation, São Paulo: Universidade de São Paulo. https://www.teses.usp.br/teses/disponiveis/55/55134/tde-01072009-225349/publico/por tf_otimo_galbuq.pdf

Baganzi, R., Kim, B. G., \& Shin, G. C. (2017). Portfolio Optimization Modelling with R for Enhancing Decision Making and Prediction in Case of Uganda Securities Exchange. Journal of Financial Risk Management, 6, 325-351. https://scirp.org/journal/PaperInformation.aspx?PaperID=80120 https://doi.org/10.4236/jfrm.2017.64024

Brooks, C., \& Kat, H. M. (2002). The Statistical Properties of Hedge Fund Index Returns and Their Implications for Investors. The Journal of Alternative Investments, 5, 26-44. https://core.ac.uk/download/pdf/6560812.pdf 
https://doi.org/10.3905/jai.2002.319053

Byrne, P., \& Lee, S. (2004). Different Risk Measures: Different Portfolio Compositions? Journal of Property Investment \& Finance, 22, 501-511. https://cutt.ly/4ve0Ckr https://doi.org/10.1108/14635780410569489

Hoe, L. W., Hafizah, J. S., \& Zaidi, I. (2010). An Empirical Comparison of Different Risk Measures in Portfolio Optimization. Business and Economic Horizons, 1, 39-45.

https://www.ceeol.com/search/article-detail?id=60122 https://doi.org/10.15208/beh.2010.06

Konno, H., \& Yamazaki, H. (1991). Mean-Absolute Deviation Portfolio Optimization Model and Its Applications to Tokyo Stock Market. Management Science, 37, 519-531. https://cutt.ly/Zve9Cti https://doi.org/10.1287/mnsc.37.5.519

Markowitz, H. (1952). Portfolio Selection. The Journal of Finance, 7, 77-91. https://doi.org/10.2307/2975974

Markowitz, H. (1959). Portfolio Selection: Efficient Diversification of Investments (Vol. 16). New York: John Wiley.

Mayanja, F. (2011). Portfolio Optimization Model: The Case of Uganda Securities EXchange (USE). Doctoral Dissertation, Dar es Salaam: University of Dar es Salaam.

Nduku, K. G. (n.d.). 2.1 Portfolio Theory.pdf-Portfolio Theory Kimundi Gillian Nduku Portfolio Theory ReCap The Efficient Frontier Portfolio Theory As I Still See / Course Hero.

Okumu, A. N., \& Onyuma, S. O. (2015). Testing Applicability of Capital Asset Pricing Model in the Kenyan Securities Market. European Journal of Business and Management, 7, 126-135.

Silva, L. P., Alem, D., \& Carvalho, F. L. (2017). Portfolio Optimization Using Mean Absolute Deviation (MAD) and Conditional Value-at-Risk (CVaR). Production, 27, e20162088.

https://www.scielo.br/scielo.php?pid=S0103-65132017000100302script=sci_arttext https://doi.org/10.1590/0103-6513.208816

Uganda Securities Exchange (n.d.). African Securities Exchanges Association.

Würtz, D., Setz, T., Chalabi, Y., Chen, W., \& Ellis, A. (2015). Portfolio Optimization with Rmetrics. Rmetrics Association \& Finance Online Publishing.

Young, M. R. (1998). A Minimax Portfolio Selection Rule with Linear Programming Solution. Management Science, 44, 673-683. https://cutt.ly/kve2m1S

https://doi.org/10.1287/mnsc.44.5.673 